\title{
Absorptive Capacity (AC), Dynamic Capabilities (DC), and Innovative Performance (IP) of Industry Locators in Laguna
}

\author{
Raymond M. Ramos \\ Batangas State University \\ raymond.ramos@g.batstate-u.edu.ph
}

\begin{abstract}
This study developed a model that identified factors that will enhance the innovative performance of Industry Locators in the Province of Laguna. Specifically, it investigated the innovative performance of industrial locators, their dynamic capability in terms of sensing, seizing and managing threats and reconfiguration. Further, the study determined as well as the industrial locators' absorptive capacity in terms of acquisition, assimilation, transformation and exploitation. To attain these goals, the researcher utilized descriptivecorrelational research design. The locale of the study is the manufacturing companies in the Philippine Economic Zones situated in Laguna. The 267 respondents consisted of team leaders who work in any of these departments in the industrial locators: research and development, planning, manufacturing, on-site assembling, engineering, maintenance and service. Based on the findings, Industrial locators in the Province of Laguna obtained high level of innovative performance, dynamic capabilities (sensing, seizing and managing threats and reconfiguration) and absorptive capacity (absorption, assimilation, transformation and exploitation). Through Structural Equation Modelling (SEM) it was found that acquisition and transformation have both direct and indirect effect to innovative performance. On the other hand, exploitation has indirect effect to innovative performance and must be mediated by dynamic capability to amplify its effect to the latter.
\end{abstract}

Keywords: absorptive capacity, dynamic capability, innovative performance, industrial locators, SEM

\section{INTRODUCTION}

The current global market has been very competitive that a firm must sustainably develop its competitive advantage. A firm's survival depends on knowledge [11], adaptability [6] and innovation [11,9]. Businesses are constantly being challenged to successfully adapt to the ever-changing business environment. This challenge is coupled with excitement on the part of the business leaders because with change, comes the opportunity to innovate. It is therefore imperative for organization leadership teams to prepare themselves to adapt successfully to a rapidly changing business environment. Companies must find ways to possess and/or enhance their capability to adapt to dynamic business environment. Organizations therefore must be adaptive and innovative in nature.

With the world on the verge of a fourth industrial revolution also known as Industry 4.0, it is expected that the pace and momentum on this evolution will be turbulent, unique and exponential. The survival and growth of a business greatly depends on how a firm will balance its innovation and market exploitation and the extent on absorbing external knowledge [8]. In addition, innovation also supports a firm's sustainability and competitiveness $[1,9]$. Teece as cited by [6], highlighted that the competitive advantage of firms in today's economy stems not from the market position but from the difficulty of competitors to replicate knowledge assets their rivals possess and the manner by which this knowledge is deployed.

Innovation is the main way to maintain a company's competitive advantages. Today, as competition has become globalized, costs of production are no longer different among companies, and the secret to success is innovation. Moreover, absorption and innovation operation are dynamic capacity for businesses and a business should have an effective knowledge management framework to promote knowledge innovation in order to succeed in the age of the competition for knowledge. An organization acquires or develops an essential index to gain new information adapted from environmental development.

\section{OBJECTIVES}


This research determined the innovative performance, absorptive capacity and dynamic capability of Industrial Locators in the province of Laguna. Moreover, it developed a structural model that will enhance the innovative performance of Industrial Locators.

\section{MATERIALS AND METHODS}

The descriptive-correlational design was employed in the study to assess the absorptive capacity, dynamic capability, and innovative performance of industrial locators. This was accomplished by virtually distributing questionnaires to the study's 267 respondents, who are either the head or team leaders of industrial locators in Laguna working in any of the following departments: research and development, planning, manufacturing, on-site assembling, engineering, maintenance, and service. Furthermore, the study utilized structured questionnaires based on [10], [4], [7], and [3, 2] to assess innovative performance, dynamic capabilities, and absorptive capacity.

The questionnaire was validated by the adviser and the panel of evaluators. After validation a pilot test among 30 respondents from industrial locators in Batangas was conducted to test the reliability of the questionnaire as measured by the Cronbach alpha. The resulting Cronbach alpha is presented in Table 1 . The data was analyzed using weighted mean and structural equation modeling.

Table 1. Reliability test of elements

\begin{tabular}{l|l|l}
\hline Elements & Number of Items & Cronbach's alpha \\
\hline Innovative Performance & 11 & .909 \\
\hline Sensing Capability & 10 & .964 \\
\hline Seizing Capability & 10 & .955 \\
\hline Managing threats and reconfiguration & 10 & .955 \\
\hline Acquisition & 10 & .964 \\
\hline Assimilation & 10 & .949 \\
\hline Transformation & 10 & .968 \\
\hline Exploitation & 10 & .992 \\
\hline
\end{tabular}

\section{RESULTS AND DISCUSSION}

\subsection{Innovative Performance}

The innovative performance of industrial locators is high with a composite mean of 3.24. The highest level of innovative performance with the mean of 3.32 was obtained on the indicator stating that industrial locators have refined their organizational structure to facilitate teamwork. The factor stating that the industrial locators have developed new products with technical specifications and functionalities which are totally different from the current ones got the lowest mean of 3.09 .

\subsection{Dynamic Capability}

The dynamic capability of industrial locators in terms of sensing capability is high with 3.29 mean. The industrial locators continually seeking and exploring new technologies, and they clearly investing resources for information study and analysis are the two factors that obtained the highest mean of 3.36. Industrial locators constantly invest in research and development activities to identify new technologies on the other hand, obtained the lowest mean of 3.22. Industrial locators seizing capability was high having obtained a mean of 3.30. The factor stating that the industrial locators take very good advantage of the opportunities obtained the highest mean of 3.36. On the other hand, the factor that states industrial locators constantly developing new products or services to take advantage of new technological and market opportunities got the lowest mean of 3.19. Lastly, in terms of Managing threats and opportunities, a mean of 3.26 was obtained indicating that industrial locators are high in this dynamic capability. The factor stating that the industrial locators adopt the right procedures to avoid transferring the technology and intellectual property of the company to their partners of got the highest mean 3.35. On the other hand, the factor stating that the industrial locators recombine their resources to adjust to changes and to the growth of the business got the lowest mean of 3.13

\subsection{Absorptive Capacity}

The absorptive capacity of industrial locators in terms of acquisition presents the factor that stated that the industrial locators easily identify the new knowledge that is most valuable to use obtained the highest mean of 3.37. While the factor that stated that the industrial locators search for relevant information concerning their industry is an every-day 
business in the company got the lowest mean of 3.16. In terms of assimilation, the factor that states that the industry locators' employees in different departments get along well when communicating with each other on matters of cross departmental concerns got the highest mean of 3.29 when they shared lingo for intracorporate communication obtained the lowest mean of 3.03. in terms of transformation, the factor which stated that the industry locators' own tools to analyze and interpret new knowledge got the highest mean of 3.33. While the factor that stated that industry locators' employees have the ability to structure and use the collected knowledge obtained the lowest mean of 3.14. Lastly, in terms of exploitation, the factor which stated that the industry locators strive to convert innovative ideas into patents got the highest mean of 3.31, on the other hand, the factor which stated that the industry locators launch innovative products/services resulting from research obtained the lowest mean of 3.14.

\subsection{AC-DC-IP Model}

Structural equation modelling (SEM) techniques was used in testing model of AC-DC-IP model. In order to ensure the measurement validity and reliability of the theoretical framework, criteria on internal consistency and indicator reliability, have been evaluated. In terms of internal consistency, all of the composite reliability values and Cronbach's $\alpha$ values were all $>0.90$ as shown in Table1. To evaluate the structural model, the collinearity was examined, the coefficient of determination $\left(\mathrm{R}^{2}\right)$, the significance of path coefficients, direct and mediation effects [5]. All of the $\mathrm{R}^{2}$ scores were above 0.1 , which further shows that multicollinearity is not an issue for the model.

Figure 1 below presents the expected model of the study based on the hypothesis drawn. Through the expected model, it aims to test the direct and indirect relationship between absorptive capacity and innovative performance and the mediating effect of dynamic capability between the two variables.

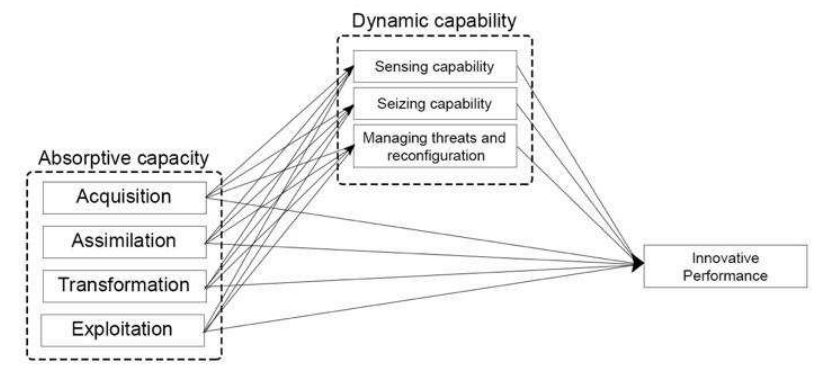

Figure 1. Expected model

Figure 2, on the other hand, presents the adjusted model generated after two runs of test, co-variance and regression weights, which were both used to come up with a good model. Compared to the expected model, the adjusted model establishes that among the three absorptive capacities, only acquisition and transformation have direct effect to innovative performance. Transformation has a negative impact on innovative performance (-.17) while acquisition has a positive impact (.19). In the case of exploitation, the adjusted model shows that exploitation has an indirect effect to innovative performance through dynamic capability. In each of the paths in the adjusted model, the estimate coefficients are shown. These estimate coefficients explain the impact of the independent to the dependent variable. All the paths shown in the adjusted model are significant.

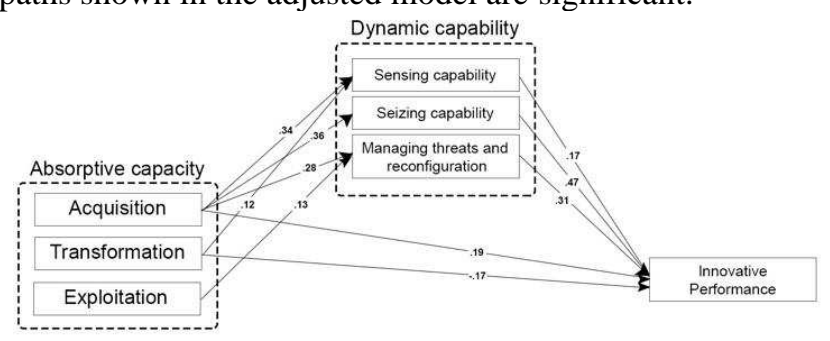

Figure 2. Adjusted model 
Table 2. Fit Measures

\begin{tabular}{l|l|l}
\hline Fit Measure & Value & Fit Index \\
\hline $\mathrm{P}$ & .76 & Good \\
\hline$\chi^{2} / \mathrm{df}$ & 1.13 & Good \\
\hline RMSEA & .02 & Good \\
\hline SRMR & .00 & Good \\
\hline GFI & .99 & Good \\
\hline CFI & .99 & Good \\
\hline NFI & .97 & Good \\
\hline AGFI & .96 & Good \\
\hline TLI & .99 & Good \\
\hline IFI & .99 & Good \\
\hline
\end{tabular}

As indicated in Table 2, the adjusted model in Figure 2 shows a good fit. This is attested by the resulting values in each of fit measures. Harrington (2008) stated that "assessing the measurement model validity occurs when the theoretical measurement model is compared with the reality model to see how well the data fits". Measurement model validity can be determined with several tools and indicators such as standardized the factor loadings, $\mathrm{t}$ statistics, chi-square test and popular goodness-of-fit indices which includes Root Mean Square Error Approximation (RMSEA), Standardized Root Mean Square Residual (SRMR), Goodness of Fit Index (GFI), the comparative fit index (CFI), Normed Fit Index (NFI), Adjusted Goodness of fit Index (AGFI), Tucker-Lewis Index (TLI), Bollen's Incremental Fit Index (IFI), and etc. It can be seen in Table 2 that the four staple measures which include chi square degree of freedom, RMSEA, SRMR, and GFI all obtained good fit measures. This implies that the suggested model from the findings of the study fits well with the theoretical factors.

Table 3. Regression for the adjusted model

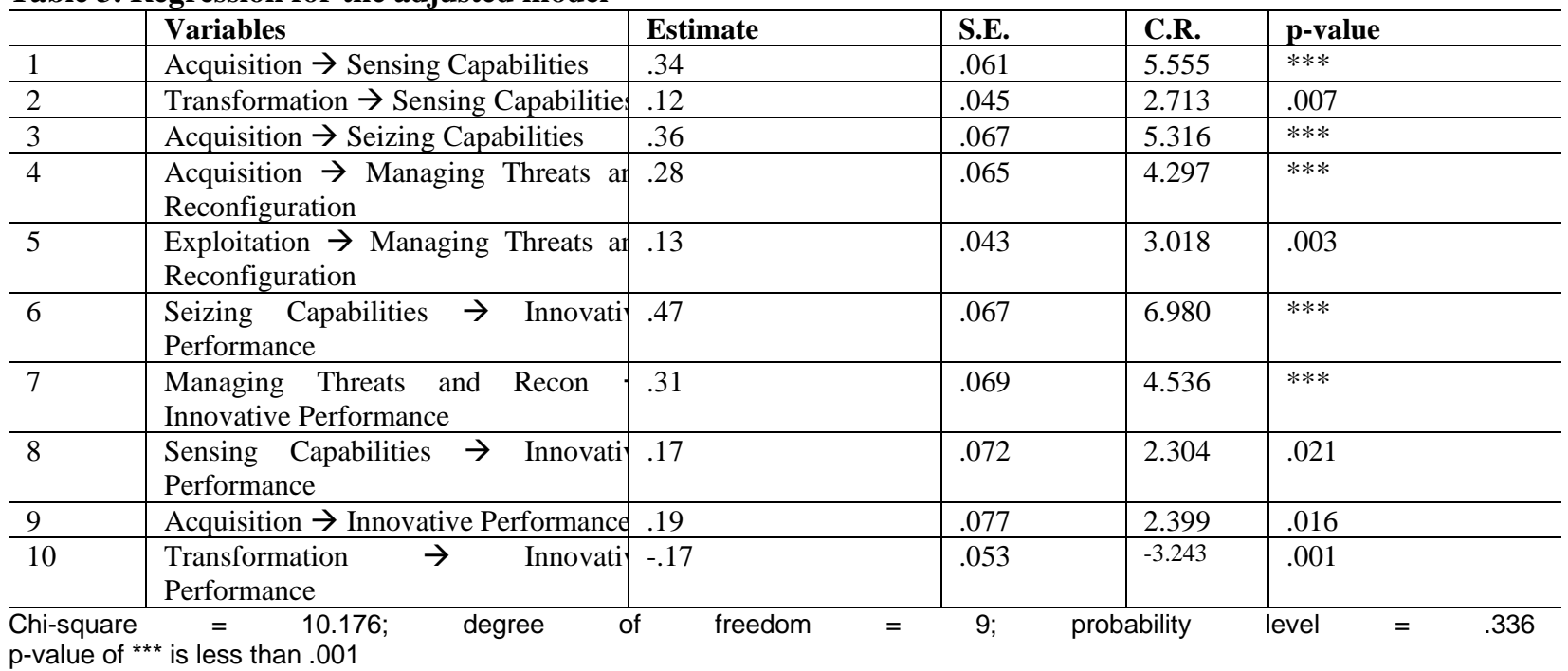

Table 3 presents the path estimates of the adjusted model which are significant as indicated by p-value less than .05 . For path 1 , this suggests that acquisition positively and significantly affects sensing capability (estimate of .34; $\mathrm{p}$-value $=* * *)$. This implies that when the industrial Locators identify and evaluate information it significantly affects the capability to develop and assess technology and opportunities in the market. Path 2 suggests that transformation positively and significantly affects sensing capability (estimate of .12; p-value $=.007$ ). Path 4 implies that acquisition positively and significantly affects managing threats and reconfiguration (estimate of .28; $p$-value = ***) the results further imply that when industrial locators continuously identify, look and evaluate knowledge outside the company, it enables growth by reassembling and reconfiguring the resources and organizational structures of companies in a constantly changing industrial environment. Meanwhile, path 5 suggests that exploitation positively and significantly affects managing threats and reconfiguration (estimate of .13 ; p-value $=.003$ ). Path 6 , on the other hand, suggests that seizing capabilities positively and significantly affects innovative performance (estimate of .47 p-value $=* * *)$. This suggest that when industrial locators made new products, services and processes, it significantly affects innovative performance. For path 7, it suggests that managing threats and reconfiguration positively and significantly affects innovative performance (estimate of .31 ; p-value $=* * *$ ). While path 8 suggests that sensing capability positively and significantly affects innovative performance (estimate of .12; $\mathrm{p}$-value $=.007$ ). Then path 9 suggests that acquisition positively and significantly affects innovative performance (estimate of .12; p- 
value $=.007)$. Surprisingly, the $10^{\text {th }}$ path indicates that transformation negatively and significantly affects innovative performance (estimate of .17 ; $\mathrm{p}$-value $=.001$ ). This suggests that the more industrial locators convert newly acquired knowledge into something purposeful, the lower their innovative performance.

Table 4. Dynamic Capabilities as Mediator between each of the Absorptive Capacities and Innovative Performance

\begin{tabular}{|c|c|c|c|c|c|c|c|}
\hline & DE & p-valu & IE & p-value & TE & p-valud & Result \\
\hline Ac to Il & .19 & .02 & .31 & .00 & .50 & .00 & $P$ \\
\hline As to II & - & - & - & - & - & - & $\mathrm{n} / \mathrm{a}$ \\
\hline $\mathrm{E}$ to IP & - & - & .04 & .00 & .04 & .00 & $\mathrm{~F}$ \\
\hline $\mathrm{T}$ to IP & -.17 & .00 & .02 & .07 & -.15 & .00 & $\mathrm{P}$ \\
\hline
\end{tabular}

Table 4, on the other hand, presents the regression of the adjusted model in Figure 2. Acquisition significantly and positively affects innovative performance while transformation negatively and significantly affects innovative performance. The direct impact of acquisition to innovative performance is .19 and that is significant with a p-value of .02. Moreover, the indirect impact of acquisition to innovative performance through dynamic capabilities is .31 and that it is significant with a p-value of .00 . Assimilation, on the other hand, presents no direct or indirect impact to innovative performance which means that the result is not applicable. This means that assimilation has no effect on innovative performance, either directly or indirectly. Exploitation obtained indirect estimates of .04 and $\mathrm{p}$ value of .00 . This implies that exploitation has indirect effect to innovative performance and must be mediated by dynamic capability to amplify its effect. The acquisition and innovative performance are partially mediated by dynamic capability. Transformation obtained direct estimate value of -.17 and the p-value of .00. Additionally, it obtained indirect estimate value of .02 and the p-value of .07. Since both p-values are lower that the level of significance of .05 , this means that both direct and indirect values are significant. The transformation and innovative performance are partially mediated by dynamic capability.

\section{RECOMMENDATION}

The following recommendations offered by the researcher based on the findings and conclusion to further enhance and strengthen absorptive capacity, dynamic capability and innovative performance of Industry Locators in the Province of Laguna

It is recommended to further improve knowledge acquisition of the firms by constantly identifying, looking and evaluating knowledge from outside the company as well as the exploration of relevant information connected to business and industry. It is also recommended to strengthen intracorporate communication, as collaboration with organizations with resources that firm can leverage can help with creating novelty products or services. Additionally, it is recommended to organize seminars and trainings that can strengthen the ability of the employees to structure and use the collected knowledge.

Transformation must be carried out effectively to avoid the adverse effect to innovative performance because of related factors like change costs, learning costs, switching costs to a new organizational system, cultural conflicts, complaints of members or work inefficiency until a new system becomes accustomed. It is hereby recommended to further enhance transforming capacity of industrial locators but attention must be given particularly on the aforecited factors while translating the existing knowledge and the newly acquired and assimilated knowledge into new process, idea or product and services. Moreover, employees must have a very high level of ability to structure and use the collected knowledge while absorbing useful and purposeful new knowledge.

It is recommended to further improve the exploitation capacity of industrial locators by trying new ways of doing things, such as searching, variation, risk-taking, experimentation, flexibility, discovery as well as providing support for the development of prototype. The industrial locators must invest in $R \& D$ to launch innovative products/services in the market resulting from well refined research.

It is recommended to improve the dynamic capability of the industrial locators by constantly investing in research and development activities to identify new technologies. This will help the firm to effectively identify changes in technological and industrial market. Moreover, it is recommended to utilize resources either raw materials or human capital in order to efficiently adjust to the changes in the environment. Knowledge obtained from the market becomes the resource that firms can use to ensure continuous innovation. Future researchers may adopt the model developed in this study in which they can anchor their investigation. 


\section{REFERENCES}

[1] Ariana, L., \& Asmara, I. J. (2018). Absorptive capacity in low-tech industry: Case study of Indonesian manufacturing companies. MATEC Web of Conferences, 215, 02005. https://doi.org/10.1051/matecconf/201821502005

[2] Arias-Pérez, J., Lozada, N. and Henao-García, E. (2020), "When it comes to the impact of absorptive capacity on coinnovation, how really harmful is knowledge leakage?", Journal of Knowledge Management, Vol. 24 No. 8, pp. 18411857. https://doi.org/10.1108/JKM-02-2020-0084

[3] Flatten, T. C., Engelen, A., Zahra, S. A., \& Brettel, M. (2011). A measure of absorptive capacity: Scale development and validation. European Management Journal, 29(2), 98-116. https://doi.org/10.1016/j.emj.2010.11.002

[4] Garrido, I., Kretschmer, C., Vasconcellos, S., \& Gonçalo, C. (2020). Dynamic capabilities: A measurement proposal and its relationship with performance. Brazilian Business Review, 17(1), 46-65. https://doi.org/10.15728/bbr.2020.17.1.3

[5] Hair Jr, J., Sarstedt, M., Hopkins, L., \& Kuppelwieser, V. (2014). Partial least squares structural equation modeling (PLSSEM). European Business Review, 26(2), 106-121. https://doi.org/10.1108/ebr-10-2013-0128

[6] Lis, A., \& Sudolska, A. (2015). Absorptive Capacity and its Role for the Company Growth and Competitive Advantage: The Case of Frauenthal Automotive Toruń Company. Journal of Entrepreneurship, Management and Innovation, 11(4), 6391.

[7] Lowik, S., Kraaijenbrink, J., \& Groen, A. J. (2017). Antecedents and effects of individual absorptive capacity: A microfoundational perspective on open innovation. Journal of Knowledge Management, 21(6), 13191341. https://doi.org/10.1108/jkm-09-2016-0410

[8] Mahmood, T., \& Mubarik, M. S. (2020). Balancing innovation and exploitation in the fourth Industrial Revolution: Role of intellectual capital and technology absorptive capacity. Technological Forecasting and Social Change, 160, 120248. https://doi.org/10.1016/j.techfore.2020.120248

[9] Pai, F-Y., \& Chang, H-F. (2013). The effects of knowledge sharing and absorption on organizationalinnovation performance - A dynamic capabilities perspective. Interdisciplinary Journal of Information, Knowledge, and Management, 8, 83-97. Retrieved from http://www.ijikm.org/Volume8 /IJIKMv8p083-097Pai0734.pdf

[10] Saunila, M. (2017). Understanding innovation performance measurement in SMEs. Measuring Business Excellence, 21(1), 1-16. https://doi.org/10.1108/mbe-01-2016-0005

[11] Senivongse, C., Bennet, A., \& Mariano, S. (2019). Clarifying absorptive capacity and dynamic capabilities dilemma in high dynamic market IT SMEs. VINE Journal of Information and Knowledge Management Systems, ahead-of-print(aheadof-print). https://doi.org/10.1108/vjikms-11-2018-0105

\section{Acknowledgements}

The researcher expresses heartfelt gratitude and appreciation to the Batangas States University CABEIHM Graduate School panel of experts, who all worked tirelessly to improve the quality of the paper through their advice and suggestions, including Bendalyn M. Landicho, Ph.D., AFBE, Teodora G. Ani, Ph.D., Gemar G. Perez, DBA, REB, Realiza M. Mame, Ph.D., and Jan Frederick Robledo. The researcher also acknowledges the employees-respondents of PEZA locators for their cooperation and consideration in responding the researcher's questionnaire despite their hectic schedules. Finally, the researcher expresses gratitude to his advisor, Lilian B. Villanueva, DBA, LPT., for her endless assistance, support, and direction during the whole study process. Thank you very much! 